\title{
Managing drug shortages during a pandemic: tocilizumab and COVID-19
}

\author{
Amol A. Verma MD MPhil, Menaka Pai MSc MD, Sudipta Saha SM, Sally Bean JD MA, Michael Fralick MD PhD, \\ Jennifer L. Gibson PhD, Rebecca A. Greenberg RN PhD, Janice L. Kwan MD MPH, Lauren Lapointe-Shaw MD PhD, \\ Terence Tang MD, Andrew M. Morris MD SM(Epi), Fahad Razak MD MSc
}

Cite as: CMAJ 2021 May 25;193:E771-6. doi: 10.1503/cmaj.210531; early released May 5, 2021

$\mathbf{T}$ he COVID-19 pandemic has revealed weaknesses in global manufacturing and distribution of medications, exacerbating many pre-existing limitations and inequities in drug supply and creating new shortages. ${ }^{1-3}$ Supply chains have been disrupted ${ }^{4}$ as many were designed for "just-in-time" management of drug inventory to reduce the costs of storage and reduce the risk of drug expiration. ${ }^{1}$ The pandemic has also led to vastly increased demand for certain medications, including the highly publicized drug hydroxychloroquine, ${ }^{5}$ which proved to be ineffective in the treatment of COVID-19, and adjunctive medications required for the care of critically ill patients such as sedatives and analgesics., ${ }^{1,2}$ The problem of mismatched supply and demand can be exacerbated by people and institutions hoarding drugs in times of supply uncertainty. ${ }^{1,2,6}$

The emergence of SARS-CoV-2 prompted testing of many newly developed or existing repurposed therapies as treatments for COVID-19. Expecting drug manufacturers to increase the supply of all candidate therapies or health care providers to stockpile inventory before drugs are proven effective would be unreasonable. Thus, when a new drug is shown to be effective, there will likely be at least a temporary shortage of supply unless it is already widely available. Medications are at greatest risk for prolonged shortage when their demand surges unexpectedly and manufacturing and distribution are not diversified. Tocilizumab is an interleukin- 6 receptor antagonist that has recently been found to reduce mortality in patients hospitalized for COVID-19. ${ }^{7}$ As the number of patients admitted to hospital with COVID-19 in Canada increases, demand for tocilizumab is on the rise and supply is likely inadequate.

We show how a health system can estimate demand for a novel therapy and assess the supply. We then discuss how the harms of drug shortage may be mitigated through use of an ethical policy framework, using tocilizumab as a case study to illustrate the potential for acute drug shortage. ${ }^{8}$

\section{What are the uses of tocilizumab and what does it cost?}

Tocilizumab is used to treat a variety of refractory rheumatologic conditions as well as cytokine release syndrome, a common and potentially life-threatening complication of chimeric antigen receptor T-cell therapy. Two large 2021 clinical trials reported that tocilizumab is an effective treatment for patients admitted to

\section{KEY POINTS}

- Drug shortages during a pandemic can result from sudden increases in demand and disruptions in supply chains.

- Health systems can rapidly respond to shortages of essential medications by estimating the clinical demand, assessing drug supply and potential inequities in access, and enacting policies grounded in an ethical framework for drug allocation.

- Tocilizumab is a life-saving therapy for adults admitted to hospital with COVID-19; demand for this drug is likely to outstrip available supply in Canada.

- We estimated that for every 1000 adults in hospital with COVID-19, 429 would be eligible for tocilizumab; treating them all may prevent 17 deaths and prevent 12 instances of invasive mechanical ventilation.

hospital with COVID-19. In the Randomized, Embedded, Multifactorial Adaptive Platform Trial for Community-Acquired Pneumonia (REMAP-CAP), treatment using tocilizumab in patients who were critically ill reduced 21-day mortality (number needed to treat $[\mathrm{NNT}]=12) .{ }^{9}$ In the Randomised Evaluation of COVID-19 Therapy (RECOVERY) trial (results not yet peer reviewed), treatment in patients who required oxygen therapy and had $\mathrm{C}$-reactive protein levels of $75 \mathrm{mg} / \mathrm{L}$ or more reduced 28-day mortality (NNT = 27). ${ }^{10}$ Expert bodies have recommended that tocilizumab be added to the standard of care for COVID-19. ${ }^{11}$

In COVID-19 clinical trials, tocilizumab was delivered intravenously, using weight-based dosing and a total dose that ranged from 400 to $800 \mathrm{mg}$ for most adults. Typically, tocilizumab treatment is with a single dose, but a second dose may be administered between 12 and 24 hours later if the patient is not improving. In the RECOVERY trial, $29 \%$ of patients received more than 1 dose..$^{10} \mathrm{~A}$ single 600-mg dose is estimated to cost $\$ 1371$ in Canada. ${ }^{12}$

\section{How might COVID-19 affect demand for tocilizumab?}

To estimate eligibility for tocilizumab, we evaluated routinely collected data for adults over 18 years of age who were admitted to hospital with COVID-19 between Jan. 1 and June 30, 2020, at 6 hospitals in Toronto and Mississauga, Ontario, Canada (Box 1). 
The RECOVERY trial included patients in hospital who required oxygen therapy and had a C-reactive protein level of $75 \mathrm{mg} / \mathrm{L}$ or more. ${ }^{10}$ The REMAP-CAP was more restrictive; it included patients who were critically ill and required cardiovascular organ support

\section{Box 1: Sample population}

Using data from the GEMINI study, ${ }^{13}$ we identified patients with COVID-19 using the enhanced Canadian version of the International Classification of Diseases and Related Health Problems, 10th Revision (ICD-10-CA) codes U07.1 and U07.2, ${ }^{14}$ as reported by hospitals to the Canadian Institute for Health Information Discharge Abstract Database. In the GEMINI study, patient vital sign data and laboratory test results were collected from electronic hospital records ${ }^{13,15}$ with $98 \%-100 \%$ accuracy across key fields. ${ }^{16}$ We excluded patients who did not have recorded vital sign measurements $(n=2,0.2 \%)$. We also excluded those who were transferred from other acute care facilities to avoid overestimating tocilizumab eligibility owing to a higher severity of illness among transferred patients, who were typically transferred for critical care $(n=83,9.2 \%)$. We divided the sample into age groups $(<50,50-59$, $60-69,70-79$ and $>79 \mathrm{yr}$ ). or high-flow oxygen therapy (defined as fraction of inspired oxygen $>0.40$, noninvasive ventilation or invasive ventilation). ${ }^{1}$ We estimated eligibility for tocilizumab in our sample based on the number of patients who met the RECOVERY criteria or required ICU admission during the first 14 days of hospital admission, as per clinical guidance for use of the drug in Ontario. ${ }^{11}$

C-reactive protein levels in our sample were ordered at the discretion of treating physicians and not for all patients. We assumed that among patients requiring supplemental oxygen who did not have a C-reactive protein level measured, the proportion with a level $75 \mathrm{mg} / \mathrm{L}$ or more (an entry criterion for the RECOVERY trial) would be the same as in patients whose values were measured. To provide a lower and upper bound on the estimate for tocilizumab eligibility, we imputed all missing results for C-reactive protein as less than $75 \mathrm{mg} / \mathrm{L}$ and $75 \mathrm{mg} / \mathrm{L}$ or more, respectively.

We evaluated data for 820 hospital admissions (Table 1) and, based on RECOVERY inclusion criteria, estimated that $42.4 \%$ of hospital admissions for COVID-19 would be eligible for tocilizumab. After we imputed missing results for C-reactive protein levels, we determined a lower bound estimate of 262 (32.0\%)

Table 1: Tocilizumab eligibility among patients admitted to hospital with COVID-19 between Jan. 1 and June 30, 2020, at 6 hospitals in Toronto and Mississauga, Ontario

No. (\%) of patients admitted to hospital with COVID-19*

\begin{tabular}{|c|c|c|c|c|c|c|}
\hline Characteristic & Overall & Aged $<50$ yr & Aged 50-59 yr & Aged 60-69 yr & Aged 70-79 yr & Aged $>79 \mathrm{yr}$ \\
\hline No. of hospital admissions & 820 & $155(18.9)$ & $126(15.4)$ & $157(19.1)$ & $164(20.0)$ & $218(26.6)$ \\
\hline Age, yr; median (IQR) & $68(54-80)$ & $40(32-45)$ & $55(53-57.75)$ & $64(62-67)$ & $74(72-77)$ & $86(82-90)$ \\
\hline Sex, female & $343(41.8)$ & $53(34.2)$ & $51(40.5)$ & $56(35.7)$ & $59(36.0)$ & $124(56.9)$ \\
\hline No. of ICU admissions & $153(18.7)$ & $25(16.1)$ & $35(27.8)$ & $41(26.1)$ & $38(23.2)$ & $14(6.4)$ \\
\hline Patients who died in hospital & $167(20.4)$ & $\leq 5(\leq 3.2) \S$ & $9(7.1)$ & $20(12.7)$ & $37(22.6)$ & $98(45.0)$ \\
\hline $\begin{array}{l}\text { Patients who met the CRP criterion/CRP } \\
\text { measured } t\end{array}$ & $\begin{array}{c}216(50.8) \\
n=425\end{array}$ & $40 / 91(44.0)$ & $41 / 73(56.2)$ & $35 / 78(44.9)$ & $46 / 83(55.4)$ & $54 / 100(54.0)$ \\
\hline Patients who met oxygenation criterion $\ddagger$ & $493(60.1)$ & $58(37.4)$ & $79(62.7)$ & $87(55.4)$ & $108(65.9)$ & $161(73.9)$ \\
\hline $\begin{array}{l}\text { Patients who were eligible for the } \\
\text { tocilizumab RECOVERY trial primary } \\
\text { estimate }\end{array}$ & $348(42.4)$ & $42(27.1)$ & $59(46.8)$ & $68(43.3)$ & $81(49.4)$ & $98(45.0)$ \\
\hline $\begin{array}{l}\text { Patients who were eligible for the } \\
\text { tocilizumab RECOVERY trial lower bound } \\
\text { estimate }\end{array}$ & $262(32.0)$ & $33(21.3)$ & $54(42.9)$ & $53(33.8)$ & $64(39.0)$ & $58(26.6)$ \\
\hline $\begin{array}{l}\text { Patients who were eligible for the } \\
\text { tocilizumab RECOVERY trial upper bound } \\
\text { estimate }\end{array}$ & $411(50.1)$ & $44(28.4)$ & $68(54.0)$ & 75 (47.8) & $94(57.3)$ & $130(59.6)$ \\
\hline $\begin{array}{l}\text { Patients who were eligible for the } \\
\text { tocilizumab RECOVERY trial complete } \\
\text { data }\end{array}$ & $\begin{array}{c}200(47.1) \\
n=425\end{array}$ & $25 / 91(27.5)$ & $40 / 73(54.8)$ & $35 / 78(44.9)$ & 49/83 (59.0) & $51 / 100(51.0)$ \\
\hline $\begin{array}{l}\text { Patients who were eligible for the } \\
\text { tocilizumab REMAP-CAP trial }\end{array}$ & $268(32.7)$ & $31(20.0)$ & $44(34.9)$ & $54(34.4)$ & $61(37.2)$ & $78(35.8)$ \\
\hline
\end{tabular}

Note: $C R P=C$-reactive protein, ICU = intensive care unit, IQR = interquartile range, RECOVERY = Randomised Evaluation of COVID-19 Therapy, REMAP-CAP = Randomized, Embedded, Multifactorial Adaptive Platform Trial for Community-Acquired Pneumonia.

*Unless stated otherwise.

TCRP level $\geq 75 \mathrm{mg} / \mathrm{L}$ at any point during their hospital stay.

fOxygen saturation on room air was $<92 \%$, required oxygen therapy or intensive care. To provide a lower and upper bound on the tocilizumab eligibility estimate, we imputed all missing CRP results as $<75$ and $\geq 75 \mathrm{mg} / \mathrm{L}$, respectively.

$\S$ Exact number suppressed to reduce risk of patient reidentification. 
and an upper bound estimate of 411 (50.1\%). Eligibility varied across age groups. Based on the more restrictive REMAP-CAP inclusion criteria, we estimated that $32.7 \%$ of hospital admissions for COVID-19 would be eligible.

We also estimated eligibility for tocilizumab by extrapolating age-specific estimates in our study population to the reported age strata for hospital admissions for COVID-19 in the United States ${ }^{17}$ and Canada. ${ }^{18}$ According to these estimates, $42.9 \%$ of patients admitted to hospital with COVID-19 in Canada and $40.9 \%$ of those in the US would be eligible for tocilizumab (lower bound estimates $31.5 \%$ and $31.2 \%$, and upper bound estimates $51.2 \%$ and $47.8 \%$, respectively; Figure 1 ). This is comparable to an estimate that $49 \%$ of patients with COVID-19 who were admitted to hospital in the United Kingdom would have been eligible for tocilizumab. ${ }^{10}$

If the third wave of the pandemic in Ontario is at least as severe as the second wave, about 7500 hospital admissions for COVID-19 might be expected. More than 3000 patients could be eligible for tocilizumab in Ontario alone. Variants of concern may result in even greater demand for the drug because the B.1.1.7 variant, which is the most prevalent in Ontario at present, is associated with a twofold greater risk of admission to the intensive care unit than the strain most prevalent earlier in the pandemic. ${ }^{19}$

\section{What might be the absolute benefits of using tocilizumab to treat COVID-19?}

Based on the estimates in our sample, of every 1000 adults admitted to hospital for COVID-19, 429 would be eligible for tocilizumab; of these, 118 (27.5\%) would be expected to die and 63 (14.8\%) would receive invasive mechanical ventilation more than 12 hours after admission. In the RECOVERY trial, the relative risk reduction for mortality was $14 \%$ (95\% confidence interval $[\mathrm{Cl}] 4 \%-23 \%)$ and for invasive mechanical ventilation was $19 \%$ (95\% Cl 5\%-32\%). ${ }^{10}$ If we consider deaths and start of ventilation that occurred more than 12 hours after admission to be potentially preventable, because patients would be unlikely to receive tocilizumab early enough to prevent events before that, treatment with tocilizumab may prevent 17 (95\% Cl 5-27) deaths and 12 (95\% Cl 3-20) instances of invasive mechanical ventilation. The absolute benefits of tocilizumab could be greater than these estimates in patients with more severe disease associated with variants of concern.

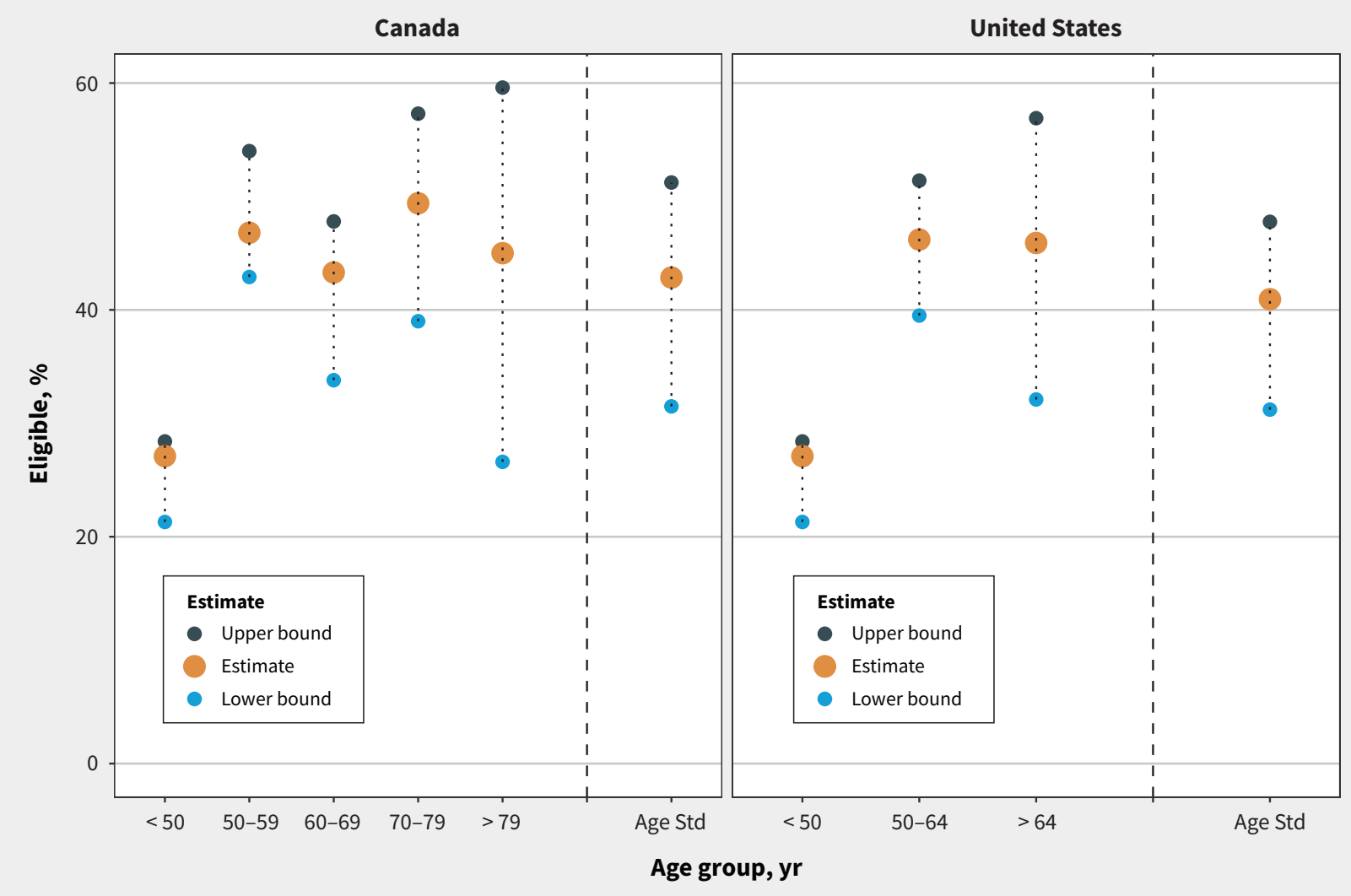

Figure 1: Age-standardized eligibility for tocilizumab in Canada and the United States. Note: Age Std = overall estimate of age-standardized eligibility for tocilizumab among patients who were admitted to hospital with COVID-19. Age-stratified hospital admissions in Canada were reported by the Government of Canada, based on cases reported to the Public Health Agency of Canada to Feb. 18, 2021. ${ }^{18}$ Age-stratified hospital admissions in the United States were reported by the COVID-19-Associated Hospitalization Surveillance Network (COVID-NET) ${ }^{17}$ to Feb. 13, 2021, which represents about $10 \%$ of the US population. To provide a lower and upper bound on the tocilizumab eligibility estimate, we imputed all missing C-reactive protein level results as less than 75 and $75 \mathrm{mg} / \mathrm{L}$ or more, respectively. 


\section{Does Canada have enough tocilizumab?}

Tocilizumab is manufactured by Hoffman-La Roche, and supply is relatively scarce in Canada and around the world. The manufacturer reported sending 1400 doses to Canada in March and 1700 in April 2021 to treat COVID-19. ${ }^{20}$ Health Canada has declared a "Tier 3 " shortage of tocilizumab, ${ }^{21}$ a designation reserved for shortages with the greatest potential impact on Canada's health care system. An international survey conducted by the European Alliance of Associations for Rheumatology in the first 4 months of the COVID-19 pandemic found that tocilizumab shortages were noted by 134 out of 980 respondents (14\%), even before publication of definitive trials. ${ }^{22}$

We are unaware of any real-time data regarding availability and use of medications across hospitals. To understand tocilizumab use and access, the Ontario COVID-19 Science Advisory Table surveyed pharmacy directors, clinical pharmacists, critical care physicians and general internal medicine physicians in 20 academic and community hospitals throughout Ontario during the week of Mar. 9-15, 2021. ${ }^{23}$ This sample was purposefully chosen to represent a range of small and large institutions across the province. It revealed that access to tocilizumab is limited and unevenly distributed. Two hospitals reported using more restrictive eligibility criteria than provincial clinical practice recommendations. Almost $30 \%$ of centres reported needing access to addi- tional tocilizumab. During the week of this survey, 15 patients did not receive treatment with tocilizumab because of concerns about inadequate supply or restrictive institutional policies.

\section{How can health systems provide equitable access to drugs that are in relative shortage?}

To provide an ethical framework for drug allocation during the pandemic, the Ontario COVID-19 Bioethics Table adapted the existing provincial framework ${ }^{8}$ for resource allocation during drug shortages. ${ }^{3}$ This approach is consistent with international frameworks, ${ }^{24}$ is based on 7 guiding ethical principles (beneficence, equity, reciprocity, solidarity, stewardship, trust and utility) and outlines 3 stages for resource allocation across the health system. Stage 1 involves serving as many people as possible by conserving and sharing supply, and increasing procurement and access. Stage 2 involves directing supply to those most likely to benefit based on existing evidence, which is the primary allocation principle. If Stage 1 and 2 efforts are insufficient to meet demand, Stage 3 involves using a fair procedure to choose between patients, which is the secondary allocation principle.

We have shown that tocilizumab is in short supply and demand for the drug may increase. There is a risk of suboptimal and inequitable distribution of this scarce resource if a dedicated systemwide procurement and allocation effort is not made. The 3 stages

\section{Stage 1: Maximize supply and sharing to maintain the standard of care}

- Create and maintain a transparent inventory of tocilizumab supply.

- Monitor and transparently report use of tocilizumab in near real time.

- Centralize procurement and allocation of tocilizumab.

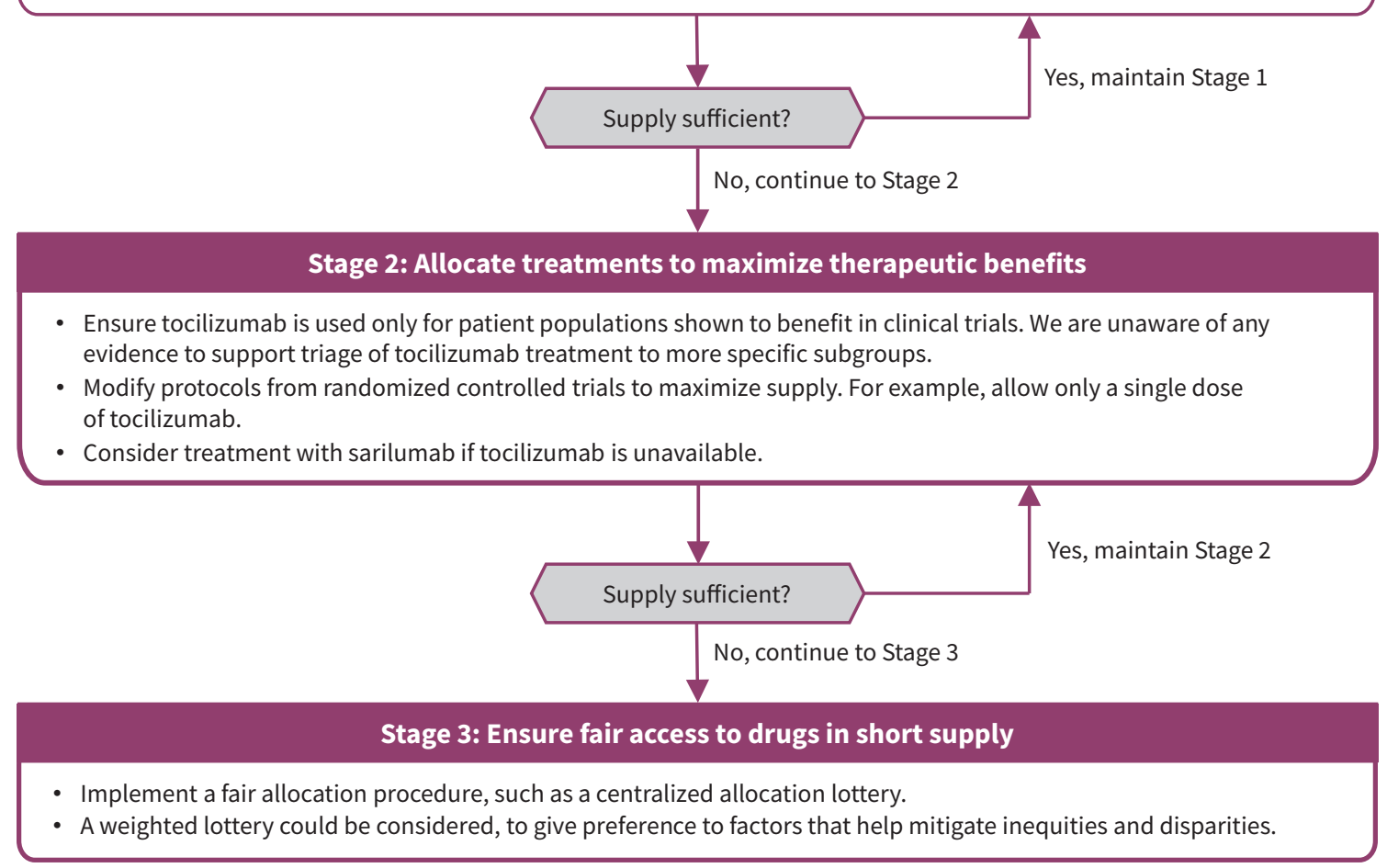

Figure 2: A proposed 3-stage framework for managing tocilizumab shortage in Canada. 
could be put into operation within health systems to manage tocilizumab supply (Figure 2). Stage 1 would include policies to create and maintain a reliable and transparent inventory of available supply of tocilizumab across the system, and monitor tocilizumab use on a near real-time dashboard. Procurement and allocation of tocilizumab would be centralized at the provincial level to maximize supply and sharing, and to avoid hoarding. Stage 2 would include ensuring treatment using tocilizumab is delivered consistently across all hospitals in accordance with evidencebased provincial recommendations, ${ }^{11}$ which generally would align with the inclusion criteria for the RECOVERY or REMAP-CAP trials. Beyond trial inclusion and exclusion criteria, we are unaware of any current evidence about whether certain subgroups of patients derive greater benefit from tocilizumab than others.

Sarilumab, another IL-6-receptor antagonist, was included in the REMAP-CAP trial, ${ }^{9}$ and may represent another treatment option for COVID-19. However, because sarilumab has been studied in fewer patients, its effect on mortality remains uncertain. ${ }^{7}$ Sarilumab supply is also limited. It is licensed and distributed in Canada as a subcutaneous injection, whereas trials studied intravenous delivery. It would be unlikely to completely address the unmet need for tocilizumab. Substituting therapy with sarilumab could be considered as a Stage 2 measure in the setting of a tocilizumab shortage.

If there is insufficient supply to meet all need and no other evidence-based ways to choose between recipients, Stage 3 may require other measures for fair distribution. For example, a centralized allocation lottery could be used. ${ }^{25}$ Lotteries may be preferred to nonrandom approaches, such as "first-come, first-served," which may perpetuate inequities by disadvantaging people who seek care later because of existing systemic or structural barriers. ${ }^{26}$ Lotteries can also be weighted to align allocation decisions with different priorities (e.g., to reduce disparities). For example, Pennsylvania endorsed a policy that would use a weighted lottery for scarce hospital medications to prioritize essential workers and people from disadvantaged areas. ${ }^{25}$ The Ontario COVID-19 Science Advisory Table has also recommended that in Stage 3, "because of the absolute scarcity, it is defensible not to offer tocilizumab to COVID-19 patients who almost certainly will not benefit. This should be based on consensus among those involved in assessing eligibility for tocilizumab allocation." 23

The potential for tocilizumab shortages has been recognized globally. ${ }^{27}$ The UK National Health Service (NHS) recommended that tocilizumab be considered for patients who meet criteria similar to those for the RECOVERY or REMAP-CAP trials. ${ }^{28}$ Provider organizations are required to register all patients receiving tocilizumab to treat COVID-19 and maintain records to show compliance with guidelines for clinical use. ${ }^{28}$ Provider organizations have also been asked to regularly update regional procurement leads and chief pharmacists about tocilizumab supply. ${ }^{29}$ Patients may only receive a single dose of tocilizumab ${ }^{28}$ and if tocilizumab is not available, treatment with sarilumab is recommended. ${ }^{30}$ The NHS policies to monitor supply and use of tocilizumab and maximize therapeutic benefit align well with our proposed framework.

\section{Conclusion}

Drug shortages during a pandemic may result from sudden increases in demand or disruptions in supply chains. Health systems can rapidly respond to shortages of essential medications by estimating the clinical demand, assessing drug supply and potential inequities in access, and enacting policies grounded in an ethical framework for drug allocation.

The COVID-19 pandemic has created a critical shortage of tocilizumab in Canada. About $40 \%$ of adults admitted to hospital with COVID-19 could be eligible to receive tocilizumab, and estimated demand from Ontario alone could outstrip the entire national supply. Determining who is most likely to benefit from tocilizumab is an urgent research priority, which may be achieved through detailed subgroup analyses and meta-analysis of existing trial evidence. If jurisdictions are unable to obtain sufficient supplies of tocilizumab, policies are needed to support evidence-based and equitable distribution. The lessons from responding to this drug shortage can inform other unexpected disruptions in drug supply and future pandemic preparedness.

\section{References}

1. Burry LD, Barletta JF, Williamson D, et al. It takes a village ....: contending with drug shortages during disasters. Chest 2020;158:2414-24.

2. Elbeddini A, Hooda N, Yang L. Role of Canadian pharmacists in managing drug shortage concerns amid the COVID-19 pandemic. Can Pharm J (Ott) 2020;153:198-203.

3. Bean S, Denburg A, Greenberg R, et al. Ethical framework for drug shortages that occur during the COVID-19 pandemic in Ontario. Toronto: University of Toronto Joint Centre for Bioethics; 2020. Available: https://jcb.utoronto.ca/ wp-content/uploads/2021/04/Ethical-Framework-for-Drug-Shortages-during -COVID-Pandemic.pdf (accessed 2021 Apr. 23).

4. Choe J, Crane M, Greene J, et al. The pandemic and the supply chain: addressing gaps in pharmaceutical production and distribution. Baltimore (MD): Johns Hopkins Bloomberg School of Public Health; 2020. Available: www.jhsph. edu/research/affiliated-programs/johns-hopkins-drug-access-and-affordability -initiative/publications/Pandemic_Supply_Chain.pdf (accessed 2021 Apr. 23).

5. Vaduganathan M, van Meijgaard J, Mehra MR, et al. Prescription fill patterns for commonly used drugs during the COVID-19 pandemic in the United States. JAMA 2020;323:2524-6.

6. Yazdany J, Kim AHJ. Use of hydroxychloroquine and chloroquine during the COVID-19 pandemic: what every clinician should know. Ann Intern Med 2020;172:754-5.

7. Ghosn L, Chaimani A, Evrenoglou T, et al. Interleukin-6 blocking agents for treating COVID-19: a living systematic review. Cochrane Database Syst Rev 2021;3:CD013881.

8. Gibson JL, Bean S, Chidwick P, et al. Ethical framework for resource allocation during a drug supply shortage. Healthc Q 2012;15:26-35.

9. The REMAP-CAP Investigators; Gordon AC, Mouncey PR, Al-Beidh F, et al. Interleukin-6 receptor antagonists in critically ill patients with COVID-19. N Engl J Med 2021 Feb. 25 [Epub ahead of print] doi: 10.1056/NEJMoa2100433.

10. RECOVERY Collaborative Group; Horby PW, Pessoa-Amorim G, Peto L, et al. Tocilizumab in patients admitted to hospital with COVID-19 (RECOVERY): preliminary results of a randomised, controlled, open-label, platform trial [preprint]. medRxiv 2021 Feb. 11. doi: 10.1101/2021.02.11.21249258.

11. Morris AM, Stall NM, Bobos P, et al.; Drugs \& Biologics Clinical Practice Guidelines Working Group; Ontario COVID-19 Science Advisory Table. Tocilizumab for hospitalized patients with COVID-19. Science Table COVID-19 Advisory for Ontario; 2021. Available: https://covid19-sciencetable.ca/sciencebrief/tocilizumab-for -hospitalized-patients-with-covid-19/ (accessed 2021 Apr. 23).

12. Formulary: Exceptional Access Program (EAP). Toronto: Ontario Ministry of Health and Ministry of Long-Term Care. Available: www.health.gov.on.ca/en/ pro/programs/drugs/odbf/odbf_except_access.aspx (accessed 2021 Feb. 27).

13. Verma AA, Guo Y, Kwan JL, et al. Patient characteristics, resource use and outcomes associated with general internal medicine hospital care: the General Medicine Inpatient Initiative (GEMINI) retrospective cohort study. CMAJ Open 2017;5:E842-9. 
14. ICD-10-CA coding direction for suspected COVID-19 cases. Ottawa: Canadian Institute for Health Information; 2020. Available: www.cihi.ca/en/bulletin/ icd-10-ca-coding-direction-for-suspected-covid-19-cases (accessed 2020 Nov. 19).

15. Verma AA, Hora T, Jung HY, et al. Characteristics and outcomes of hospital admissions for COVID-19 and influenza in the Toronto area. CMAJ 2021;193:E410-8.

16. Verma AA, Pasricha SV, Jung HY, et al. Assessing the quality of clinical and administrative data extracted from hospitals: the General Medicine Inpatient Initiative (GEMINI) experience. J Am Med Inform Assoc 2021;28:578-87.

17. Laboratory-confirmed COVID-19-associated hospitalization. Atlanta: Centers for Disease Control and Prevention. Available: https://gis.cdc.gov/grasp/ COVIDNet/COVID19_5.html (accessed 2021 Feb. 20).

18. COVID-19 daily epidemiology update. Ottawa: Public Health Agency of Canada; modified 2021 Apr. 20. Available: https://health-infobase.canada.ca/covid-19/ epidemiological-summary-covid-19-cases.html (accessed 2021 Feb. 20).

19. Tuite AR, Fisman DN, Odutayo A, et al. Ontario COVID-19 Science Advisory Table. COVID-19 hospitalizations, ICU admissions and deaths associated with the new variants of concern. Science Table COVID-19 Advisory for Ontario; 2021. Available: https://covid19-sciencetable.ca/sciencebrief/covid-19 -hospitalizations-icu-admissions-and-deaths-associated-with-the-new-variants -of-concern/ (accessed 2021 Apr. 23).

20. Grant K. Hospitals running out of key drug for COVID-19 patients. The Globe and Mail 2021 Apr. 8. Available: www.theglobeandmail.com/canada/article -drug-critical-to-covid-19-patients-being-rationed-in-ontario/ (accessed 2021 Apr. 23).

21. Exceptional importation and sale of drugs in relation to COVID-19: Tier 3 drug shortages. Ottawa: Health Canada; modified 2021 Mar. 31. Available: www. canada.ca/en/health-canada/services/drugs-health-products/compliance -enforcement/covid19-interim-order-drugs-medical-devices-special-foods/ information-provisions-related-drugs-biocides/tier-3-shortages.html (accessed 2021 Apr. 9).
22. Dejaco C, Alunno A, Bijlsma JWJ, et al. Influence of COVID-19 pandemic on decisions for the management of people with inflammatory rheumatic and musculoskeletal diseases: a survey among EULAR countries. Ann Rheum Dis 2020 Nov. 6 [Epub ahead of print]. doi: 10.1136/annrheumdis-2020-218697.

23. Morris AM, Bean S, Bell CM, et al. Drugs \& Biologics Clinical Practice Guidelines Working Group; Ontario COVID-19 Science Advisory Table. Strategies to manage tocilizumab supply during the COVID-19 pandemic. Science Table COVID19 Advisory for Ontario; 2021. Available: https://covid19-sciencetable.ca/ sciencebrief/strategies-to-manage-tocilizumab-supply-during-the-covid-19 -pandemic/ (accessed 2021 Apr. 20).

24. Emanuel EJ, Persad G, Upshur R, et al. Fair allocation of scarce medical resources in the time of COVID-19. N Engl J Med 2020;382:2049-55.

25. White DB, Angus DC. A proposed lottery system to allocate scarce COVID-19 medications: promoting fairness and generating knowledge. JAMA 2020; 324:329-30.

26. DeJong $\mathrm{C}$, Chen $\mathrm{AH}$, Lo B. An ethical framework for allocating scarce inpatient medications for COVID-19 in the US. JAMA 2020;323:2367-8.

27. Murthy S, Lee TC. IL-6 blockade for COVID-19: a global scientific call to arms. Lancet Respir Med 2021 Mar. 4 [Epub ahead of print]. doi: 10.1016/ S2213-2600(21)00127-2.

28. Interim clinical commissioning policy: tocilizumab for hospitalised patients with COVID-19 pneumonia (adults) [news release]. London (UK): NHS; 2021 Feb. 21. Available: www.england.nhs.uk/coronavirus/wp-content/uploads/ sites/52/2021/02/C1143-interim-clinical-commissioning-policy-tocilizumab-rps -v2.pdf (accessed 2021 Apr. 23).

29. Robinson J. Guidance on off-label use of tocilizumab for UK COVID-19 patients published. Pharm J 2020;305. doi: 10.1211/PJ.2020.20208597.

30. COVID-19 rapid guideline: managing COVID-19. London (UK): National Institute for Health and Care Excellence; 2021. Available: www.nice.org.uk/guidance/ ng191 (accessed 2021 Apr. 23).
Competing interests: Amol Verma and Fahad Razak are part-time employees of Ontario Health. Menaka Pai, Andrew Morris, Jennifer Gibson and Fahad Razak are members of the Ontario COVID-19 Science Advisory Table. Sally Bean and Jennifer Gibson are members of the Ontario COVID-19 Bioethics Table. Michael Fralick is a co-investigator for the SOLIDARITY clinical trial. He also received consultant fees from Pine Trees Health that has developed a CRISPR-based point-of-care diagnostic test for COVID-19. No other competing interests were declared.

This article has been peer reviewed.

Affiliations: Li Ka Shing Knowledge Institute (Verma, Saha, Razak), St. Michael's Hospital, Unity Health Toronto; Department of Medicine (Verma, Fralick, Kwan, Lapointe-Shaw, Tang, Morris, Razak); Institute of Health Policy, Management and Evaluation (Verma, Gibson, Razak); Dalla Lana School of Public Health (Bean, Gibson); Joint Centre for Bioethics (Bean, Gibson); and Department of Paediatrics (Greenberg), University of Toronto; Sunnybrook Health Sciences Centre (Bean); Sinai Health System (Fralick, Greenberg, Kwan, Morris); Department of Medicine (Lapointe-Shaw), and Toronto General Hospital Research Institute (Lapointe-Shaw), University Health Network; Women's Institute for Health System Solutions and Virtual Care (Lapointe-Shaw), Women's College Hospital; ICES Central (LapointeShaw); Institute for Better Health (Tang), Trillium Health Partners; Division of Infectious Diseases (Morris), Sinai Health System and
University Health Network, Toronto, Ont.; Department of Medicine (Pai), McMaster University; Hamilton Regional Laboratory Medicine Program (Pai); Hamilton Health Sciences (Pai), Hamilton, Ont.

Contributors: Amol Verma, Menaka Pai and Sudipta Saha are first co-authors, with equal contributions. Andrew Morris and Fahad Razak are senior co-authors, with equal contributions. Amol Verma, Menaka Pai, Sudipta Saha, Andrew Morris and Fahad Razak designed the analysis, with substantial input from all authors. Amol Verma wrote the first draft of the manuscript. Sudipta Saha performed the data analysis. Amol Verma, Michael Fralick, Janice Kwan, Lauren Lapointe-Shaw, Terence Tang and Fahad Razak led data collection from each hospital. Sally Bean, Jennifer Gibson and Rebecca Greenberg developed the ethical framework for allocation of scarce resources during drug shortages in a pandemic and informed its application to tocilizumab. All of the authors revised the manuscript critically for important intellectual content, gave final approval of the version to be published and agreed to be accountable for all aspects of the work.

Funding: This project was supported by Canadian Institutes of Health Research (CIHR) grant VR4-172743 provided to Amol Verma, Fahad Razak, Michael Fralick, Lauren LapointeShaw and Terence Tang. Amol Verma is supported by an AMS Healthcare Fellowship in Compassion and Artificial Intelligence. Lauren Lapointe-Shaw received a grant from the Department of Medicine COVID-19 Funding Opportunity, University of Toronto.

The development of the GEMINI data platform was supported with funding from the Canadian Cancer Society, the Canadian Frailty Network, ClHR, the Natural Sciences and Engineering Research Council of Canada, Ontario Health, the St. Michael's Hospital Association Innovation Fund, the University of Toronto Department of Medicine, and in-kind support from partner hospitals and Vector Institute to Amol Verma and Fahad Razak.

Data sharing: Data from GEMINI can be accessed upon request to the corresponding author, to the extent that is possible in compliance with local research ethics board requirements and data-sharing agreements.

Acknowledgement: The authors thank Bradley Langford, Elizabeth Leung and Sumit Raybardhan for their role in leading the survey of tocilizumab use in Ontario hospitals.

Content licence: This is an Open Access article distributed in accordance with the terms of the Creative Commons Attribution (CC BY-NC-ND 4.0) licence, which permits use, distribution and reproduction in any medium, provided that the original publication is properly cited, the use is noncommercial (i.e., research or educational use), and no modifications or adaptations are made. See: https://creativecommons. org/licenses/by-nc-nd/4.0/

Correspondence to: Amol Verma, amol.verma@mail.utoronto.ca 